\title{
Delayed salicylate toxicity following enteric-coated acetylsalicylic acid overdose: a case report and review of the literature
}

\author{
Robert Drummond, MD;* Nadine Kadri, MD;† Julie St-Cyr, MD $\S$
}

\begin{abstract}
Salicylates are widely available and potentially lethal. Clinical and laboratory findings associated with enteric-coated acetylsalicylic acid (ECASA) ingestion may be delayed more than 24 hours. When dealing with patients who have a history of significant ingestion, emergency physicians should consider initiating therapy regardless of initial salicylate levels. Prolonged observation may be necessary in cases of suspected ECASA overdose.

RÉSUMÉ : Les salicylés sont fort répandus et potentiellement fatals. Les constatations cliniques et les résultats de laboratoire associés à l'ingestion d'AAS entérosoluble peuvent être retardés pendant plus de 24 heures. Au moment de traiter des patients ayant des antécédents d'ingestion importante, les médecins d'urgence devraient songer à commencer le traitement peu importe les niveaux initiaux de salicylés. Une observation prolongée peut s'imposer dans certains cas d'intoxication à l'AAS soupçonnée.
\end{abstract}

Key words: acetylsalicylic acid, salicylate, intoxication, overdose

\section{Introduction}

Salicylate overdoses are potentially life-threatening toxicological emergencies. Enteric-coated acetylsalicylic acid (ECASA) is a sustained-release salicylate preparation formulated to resist acidic gastric secretions and to dissolve in the alkaline medium of the small intestine rather than in the stomach. This delay in absorption is intended to decrease the GI side effects associated with ASA therapy.

The Done nomogram is widely used to predict the significance of a salicylate overdose if the time of ingestion is known. ${ }^{1}$ However, the nomogram is only helpful in acute, single-dose ingestions. Previous authors have shown that it is not applicable to ECASA overdose and, therefore, that prolonged observation may be warranted in these cases..$^{2-5}$
This paper reports a case of Entrophen ${ }^{\circledR}$ overdose that led to delayed toxicity despite early gastrointestinal (GI) decontamination and 24-hour observation in the emergency department (ED). This case confirms the inappropriateness of the Done nomogram in the setting of ECASA overdose and suggests that the optimal observation period has yet to be defined.

\section{Case report}

A 21-year-old woman, well known to the psychiatry service, presented to the $\mathrm{ED}$ at 15:00 hours after intentionally ingesting 60 tablets of 500-mg Entrophen ${ }^{\circledR}$ (ECASA) 2 hours earlier. On admission, she had no complaints and no symptoms of salicylism. On physical examination, her vital

\footnotetext{
*Department of Emergency Medicine, St. Mary's Hospital, Montreal, Que.; †Resident, Medical Biochemistry, McGill University, Montreal; $\S$ Department of Medical Biochemistry, St. Mary's Hospital, Montreal

Received: Feb. 9, 2000; final submission: July 26, 2000; accepted: July 26, 2000.

This article has been peer reviewed.
} 
signs were: pulse 86 beats/min, blood pressure 124/90 mm $\mathrm{Hg}$, respirations 20 breaths/min, and temperature $37.1^{\circ} \mathrm{C}$ orally. Neurological, cardiac, respiratory and abdominal examinations were all normal.

The patient underwent gastric lavage with $4 \mathrm{~L}$ of distilled water. No pill fragments were returned, and $100 \mathrm{~g}$ of activated charcoal was administered. Because of the patient's stable condition, intravenous sodium bicarbonate was not given. Initial laboratory investigations included: sodium $140 \mathrm{mmol} / \mathrm{L}$, potassium $3.3 \mathrm{mmol} / \mathrm{L}$, chloride $105 \mathrm{mmol} / \mathrm{L}$, $\mathrm{HCO}_{3} 29.6 \mathrm{mmol} / \mathrm{L}, \mathrm{BUN} 4.7 \mathrm{mmol} / \mathrm{L}$ urea, creatinine 63 $\mathrm{mmol} / \mathrm{L}$, and glucose $3.6 \mathrm{mmol} / \mathrm{L}$. Arterial blood gas testing revealed a pH of 7.38, $\mathrm{PO}_{2}$ of $100 \mathrm{~mm} \mathrm{Hg}, P_{\mathrm{CO}_{2}}$ of 40 $\mathrm{mm} \mathrm{Hg}$ and total $\mathrm{CO}_{2}$ of $24 \mathrm{mmol} / \mathrm{L}$. The ASA level at this time was less than $0.3 \mathrm{mmol} / \mathrm{L}$, as performed on the CX7 Delta using the salicylate hydroxylase method (Beckman Instruments, Brea, Calif.).

The patient was observed overnight in the ED. ASA levels were drawn 3 times: at 19:18 $(0.1 \mathrm{mmol} / \mathrm{L})$, at 22:17 $(0.1 \mathrm{mmol} / \mathrm{L})$ and at $14: 26$ the next afternoon $(0.5 \mathrm{mmol} / \mathrm{L})$. After 24 hours of ED monitoring, at 15:30 on the day after presentation, she was discharged in the care of her family. Six hours after discharge ( 32 hours post-ingestion), she returned with a chief complaint of tinnitus for 4 hours. At this time, she denied further ingestions of any kind and family members confirmed that she no longer had access to salicylate preparations. Her vital signs and physical examination were unchanged. Laboratory investigations revealed: sodium $144 \mathrm{mmol} / \mathrm{L}$; potassium $3.4 \mathrm{mmol} / \mathrm{L}$; chloride 111 $\mathrm{mmol} / \mathrm{L} ; \mathrm{HCO}_{3} 23.2 \mathrm{mmol} / \mathrm{L}$; BUN $3.0 \mathrm{mmol} / \mathrm{L}$ urea; creatinine $70 \mathrm{mmol} / \mathrm{L}$; glucose $5.0 \mathrm{mmol} / \mathrm{L}$, and ASA level 5.1 mmol/L. Arterial blood gases showed: $\mathrm{pH}$ 7.46, $\mathrm{PO}_{2} 119$ $\mathrm{mm} \mathrm{Hg}, \mathrm{PCO}_{2} 29 \mathrm{~mm} \mathrm{Hg}$, and total $\mathrm{CO}_{2} 20 \mathrm{~mm} \mathrm{Hg}$. A flat plate of the abdomen was reported as normal, with no radiopaque pill fragments visualized.

After discussion with the regional poison control centre, it was decided that the patient should undergo serum alkalinization and dialysis. She made an uneventful recovery and was discharged 48 hours later.

\section{Discussion}

The Done nomogram was designed to predict the severity of ASA toxicity and to guide therapy in cases where ingestion time is known. There are, however, several limitations to its use. First, the nomogram was not developed with enteric-coated or sustained-release products in mind, and it was derived in a pediatric population, where most patients were less than 15 years of age. Because children tend to present with earlier and more marked metabolic acidosis, the nomogram may be less predictive in adults. ${ }^{6}$ As Done pointed out in his 1960 paper, ${ }^{1}$ the nomogram was developed for use in acute, single-dose ASA ingestions. It should not be applied to patients who have taken repeated doses or who use ASA therapeutically. In these cases, several factors limit nomogram validity. Chronic or multiple-dose salicylate ingestion tends to cause acidemia. In acidic milieu, salicylates (weak acids) become non-polar and gain increased capacity to penetrate biological membranes and accumulate in tissue. The result is that blood levels may be disproportionately low, and toxicity more severe than predicted by the nomogram. In addition, with high or repeated doses, salicylate metabolic and elimination pathways become saturated. As ASA concentrations rise, first-order kinetics become zero-order kinetics. ${ }^{7}$ Elimination rate becomes relatively fixed and fails to increase with increasing salicylate levels. ${ }^{8}$ This explains why, at therapeutic levels, serum halflife is $2-4$ hours, while in toxic ingestions, half-life may be up to 20 hours. ${ }^{1}$ Unfortunately, Done's nomogram is based on the assumption that salicylates are eliminated solely by first-order kinetics.

Not surprisingly, the nomogram has been shown to have poor predictive value in some studies. Dugandzic and colleagues ${ }^{9}$ applied it retrospectively to 55 (predominantly adult) patients with salicylate intoxication and found that it correlated poorly with clinical severity. This was particularly true in the moderate and severe categories where the nomogram tended to overestimate the severity of the intoxication.

It is now standard teaching that the Done nomogram does not apply to cases of ECASA overdose and that a period of clinical observation is warranted. Although 24 hours is generally considered prudent, it is by no means definitive. A review of the literature yields only a handful of case reports describing ECASA overdose; therefore, it is not surprising that there is a lack of consensus about the optimal period of observation.

Todd and coworkers ${ }^{2}$ reported delayed toxicity in 2 children, aged 13 months and 6 years, who ingested Safapyrn ${ }^{\circledR}$ (ECASA and acetaminophen). The peak salicylate level of $3.98 \mathrm{mmol} / \mathrm{L}$ occurred at 25 and 60 hours respectively. The older child was very toxic and, despite gastric lavage, required positive pressure ventilation and peritoneal dialysis for acute renal failure. In this patient, acetaminopheninduced hepatic toxicity may have further delayed salicylate excretion.

In 1983, Kwong and coworkers ${ }^{3}$ described a 25-year-old woman who ingested approximately $30 \mathrm{~g}$ of ECASA. She vomited spontaneously but had no GI decontamination. Her salicylate levels peaked 30 hours later at $4.34 \mathrm{mmol} / \mathrm{L}$, and she had moderately severe symptoms that would not have 
been predicted by 6-hour salicylate levels but would have been predicted by 24-hour levels (plotted on a standard Done nomogram).

Wortzman and Grunfeld ${ }^{4}$ reported a 22-year-old man who presented 1 hour after ingesting $29 \mathrm{~g}$ of ECASA. Ipecac was administered, but no pill fragments were evident in the vomitus. At 3 hours, despite being asymptomatic with a normal physical examination, he was treated with serum alkalization, gastric lavage and activated charcoal. At this time, his salicylate level was zero; however, it rose to 1.0 $\mathrm{mmol} / \mathrm{L}$ at 7 hours and peaked at $2.6 \mathrm{mmol} / \mathrm{L}$ at 24 hours.

In 1991, Pierce and colleagues ${ }^{5}$ reported a 14-year-old girl who ingested $10 \mathrm{~g}(189 \mathrm{mg} / \mathrm{kg})$ of ECASA. Three hours after ingestion, despite being asymptomatic, she was treated with ipecac, activated charcoal, whole-bowel irrigation and serum alkalization. Her 3-hour salicylate level was 2.49 $\mathrm{mmol} / \mathrm{L}$, but, in spite of aggressive therapy, it peaked at $3.48 \mathrm{mmol} / \mathrm{L}$ at 24 hours.

The paucity of ECASA data precludes development of optimal observation guidelines, but a 1981 Lancet editorial recommends 24 hours of observation after ECASA ingestion..$^{10}$ In the cases described above, 24 hours of observation would have been adequate because all patients had clinical findings or toxic salicylate levels within this time frame. However, the case presented in this article is disturbing because, despite GI decontamination and 24 hours of observation, our patient re-presented 32 hours after ingestion with new symptoms and a rising, moderately toxic salicylate level.

There are other possible explanations for our patient's delayed toxicity, but these are unlikely. A second ASA ingestion might have occurred after discharge; however, the patient steadfastly denied this (and she had readily volunteered all information about the initial ingestion). In addition, her parents insisted that she had no access to additional salicylates and that a second exposure was not possible.

Bezoar formation is also a consideration. Although uncommon, pharmacologic bezoars can occur after ingestion of large amounts of ECASA. In general, salicylism develops in ECASA ingestions when ingested tablets reach the duodenum, where alkaline secretions rapidly dissolve the cellulose acetate phthalate coating. Most reported cases of ECASA bezoar formation are associated with gastric outlet obstruction. ${ }^{11-13}$ In these cases, the coating would dissolve more slowly because of the acid milieu. Although our patient's x-rays showed no evidence of bezoar formation, she did not undergo gastroscopy and we cannot exclude this possibility with certainty. A final possibility is that her activated charcoal dose was suboptimal, although given the prolonged gastric retention and delayed absorption seen with ECASA overdoses, this seems unlikely.

\section{Conclusions}

This case provides further evidence that the Done nomogram should not be used in the assessment of ECASA ingestions, and that a period of observation greater than 24 hours may be necessary if a significant ingestion is thought to have occurred. Furthermore, when dealing with patients who have a history of significant ingestion, physicians should consider initiating therapy regardless of the initial salicylate levels.

\section{References}

1. Done AK. Salicylate intoxication: significance of measurements of salicylate in blood in cases of acute ingestion. Pediatrics 1960;26:800-7.

2. Todd PJ, Sills JA, Harris F. Problems with overdoses of sustained release aspirin. Lancet 1981;1:777.

3. Kwong TC, Laczin J, Baum J. Self-poisoning with enteric-coated aspirin. Am L Clin Path 1983;80:888-90.

4. Wortzman DJ, Grunfeld A. Delayed absorption following enteric-coated aspiring overdose. Ann Emerg Med 1987;16:434-6.

5. Pierce RP, Gazewood J, Blake RL. Salicylate poisoning from enteric-coated aspirin. Postgrad Med 1991;89:61-4.

6. Gaudreault P, Temple AR, Lovejoy FH. The relative severity of acute versus chronic salicylate poisoning in children: a clinical comparison. Pediatrics 1982;70:566-9.

7. Needs CJ, Brooks PM. Clinical pharmacokinetics of the salicylates. Clin Pharmacokinet 1985;10:164-77.

8. Levy G. Clinical pharmacokinetics of salicylates: a reassessment. Br J Clin Pharmacol 1980;10:285S-290S.

9. Dugandzic RM, Tierney MG, Dickinson GE, Dolan MC, McKnight DR. Evaluation of the validity of the Done nomogram in the management of acute salicylate intoxication. Ann Emerg Med 1989;18:1186-90.

10. Poisoning with enteric-coated aspirin [editorial]. Lancet 1981; 2:130.

11. Baum J. Enteric-coated aspirin and the problem of gastric retention. J Rheumatol 1984;11:250.

12. Bogacz K, Caldron P. Enteric-coated aspirin bezoar: elevation of serum salicylate by barium study. Am J Med 1987;83:783-6.

13. Taylor JR, Streetman DS, Castle SS. Medication bezoars: a literature review and report of a case. Ann Pharmacother 1998; 32:940-6.

Correspondence to: Dr. Robert Drummond, St. Mary's Hospital, 3830 Lacombe Ave., Montreal QC H3T 1M5 